were also a few cases in which a patient having treatment for chronic trachoma (stage iii) developed this affection, which cleared up quickly without affecting the course of the trachomatous condition in any way.

$\therefore$ Invariably the seat of trouble was the muco-cutaneous junction along the margin of the lids, or the bulbar conjunctiva adjoining the outer canthus along the palpebral fissure.

I am indebted to the Adviser, Medical Services, Malay States, for permission to publish this paper.

\title{
REFERENCES
}

WRight, R. E.--" Superficial punctate keratitis." Brit. Jl. of Ophthal., June, 1930.

KIRWAN, E. W. O'G.- "Epidemic superficial punctate keratitis in Bengal." Folia Ophthai. Orientalia, September-December, 1934.

\section{INFECTION OF SPHENOIDAL SINUSES WITH SECONDARY AFFECTION OF THE EYES* \\ Causing in one detachment of the retinae in both eyes, and in the other acute optic neuritis of one eye}

BY

\author{
E. W. ARNDT \\ PERTH, WESTERN AUSTRALIA \\ (LATE SURGEON-IN-CHARGE, VICTORIA MEMORIAL. \\ EYE HOSPITAL, COLOMBO)
}

Case 1.-Mrs. C., aged 32 years. Wife of a doctor, first seen about June 22, 1937, complaining of a severe pain behind the right eye and across the forehead, and diffuse redness and swelling of the face. She had had the previous week a mild attack of cold, cough and fever, possibly influenza, which was treated with "home" remedies. She said she had been subject to " hay fever," i.e., rather long bouts of sneezing on waking in the mornings and occasionally at odd times in the day, for some years.

Personal History.- No illness of any note. Had three children, eldest about six years old. All healthy.

FAMily History.-Negative.

The eyes appeared normal, movements good. T.n. Fundi normal. Tenderness on pressure over the right eye.

She was given sod. salicyl. and ordered fomentations. The patient was seen two days later and her sight was much diminished 
and she was in much pain. On this occasion the condition of the eye was much the same, but vision was reduced to about $3 / 60$ for each eye. T.n. R. and L. Fundi appeared normal. Fields not tested owing to the pain the patient had. Tenderness was present on backward pressure on the eye, on both sides.

A diagnosis of retrobulbar neuritis was made and the patient admitted to hospital. Within a few days sight had diminished to H.M., R. and L., but slowly improved to 6/18 R. and L. after about 8 days in hospital. Treated with sod. salicyl. in large doses and fomentations.

Meanwhile the usual examinations of blood, sputum, and urine, were carried out with negative results.

After a few days in this state, sight began to fail again. At this stage a report by an ear, nose and throat surgeon was that all sinuses were clear. X-Ray examination appeared to confirm this.

On lumbar puncture the fluid was found to be at normal pressure, and the examination of the fluid gave negative results for Wassermann and Kahn tests, and there was no change in contents.

At a second examination a few days later the sphenoidal sinuses were reported to be infected and an operation recommended for this condition. The sight of the patient was at this time about 2/60 R. and L.

The patient was transferred to the General Hospital under the care of Dr. A. M. de Silva, Hon. Consulting Surgeon, Ear, Nose and Throat Department, who operated on her next morning, Friday, July 9. The left sphenoidal sinus was first dealt with under local anaesthesia. At the operation the mucous membrane of the sinus was found.very congested and a bead of pus seen. The sinus was opened thoroughly and efficient drainage established.

The patient kept well and comfortable that day and the next, and on the evening of the next day, i.e., Saturday, one short wave diathermy treatment was given her.

I was unable to see the patient for two days, and on examination found to my dismay extensive retinal detachments in the lower halves of both eyes. The detachments were tense and large, bulging up towards the pupil, extending from near the discs to beyond the range of vision by the direct method. The nasal condition was satisfactory - no pus was to be seen in the left sinus.

The patient was ordered atropine and fomentations to the eyes and given sod. iodide internally. Absolute rest in the semirecumbent position was ordered.

On Thursday, July 15, as the eye condition had not got worse, and clearing of the right sphenoidal sinus was considered necessary, the patient was operated on again under local anaesthesia. The right sinus was seen to be very deeply congested-no pus was seen. The sinus was well opened and good drainage established. 
That day no further complications occurred in the eyes.

The same treatment as before was continued, the patient very rigidly kept in a semi-recumbent position.

For various reasons, chief of which was lack of a suitable reliable machine for operating, it was decided to adopt conservative measures for so long as no further complications were noticed nor further diminution in sight.

The patient continued in the same state for about a month and then it seemed that the detachments were beginning to lessen in size and prominence. At this stage diathermy was given to both eyes, in addition to the treatment already being carried out, and calcium intra-muscularly, from time to time.

The patient made an uneventful recovery, both detachments were completely reposed leaving that part of the retinae which took part in the detachments looking like " the shore at the ebb of the tide" - mottled and marked all over with pigment and spots of exudate.

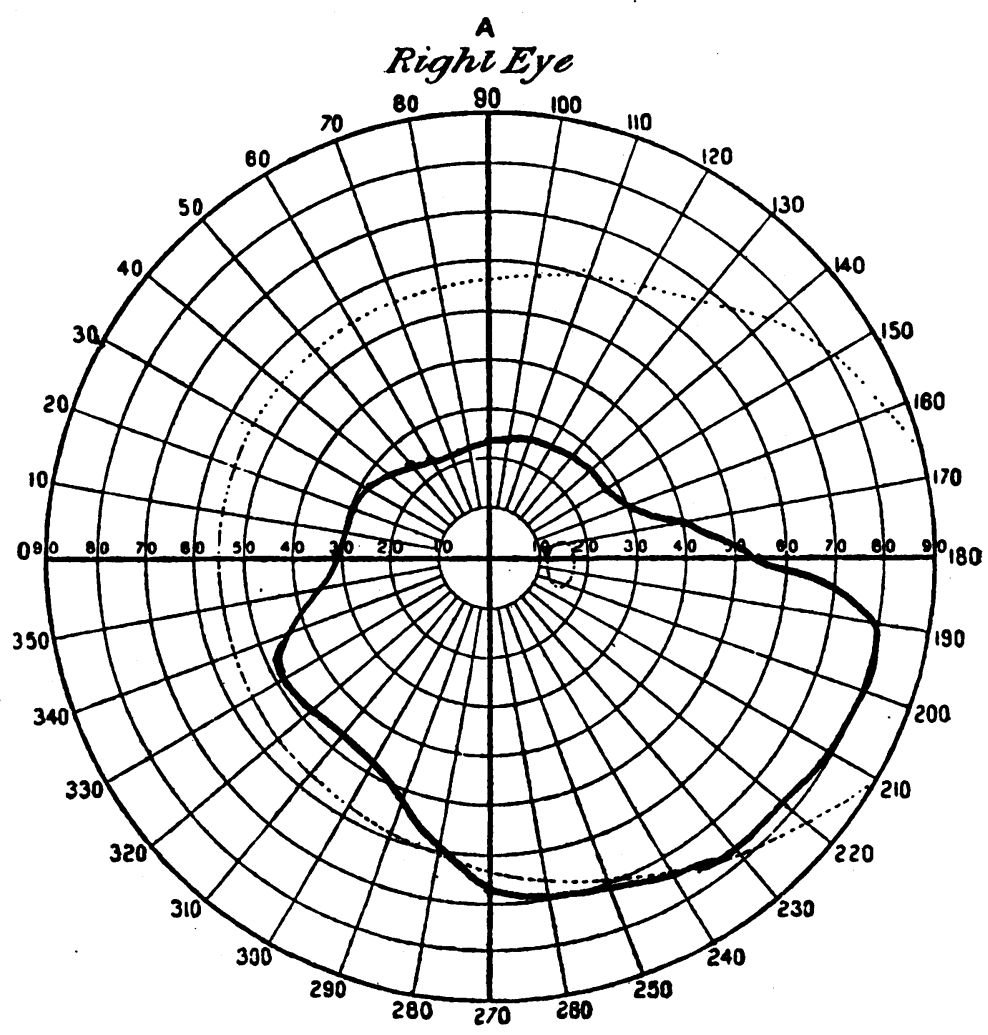

Mrs. C., November 8, 1937. 


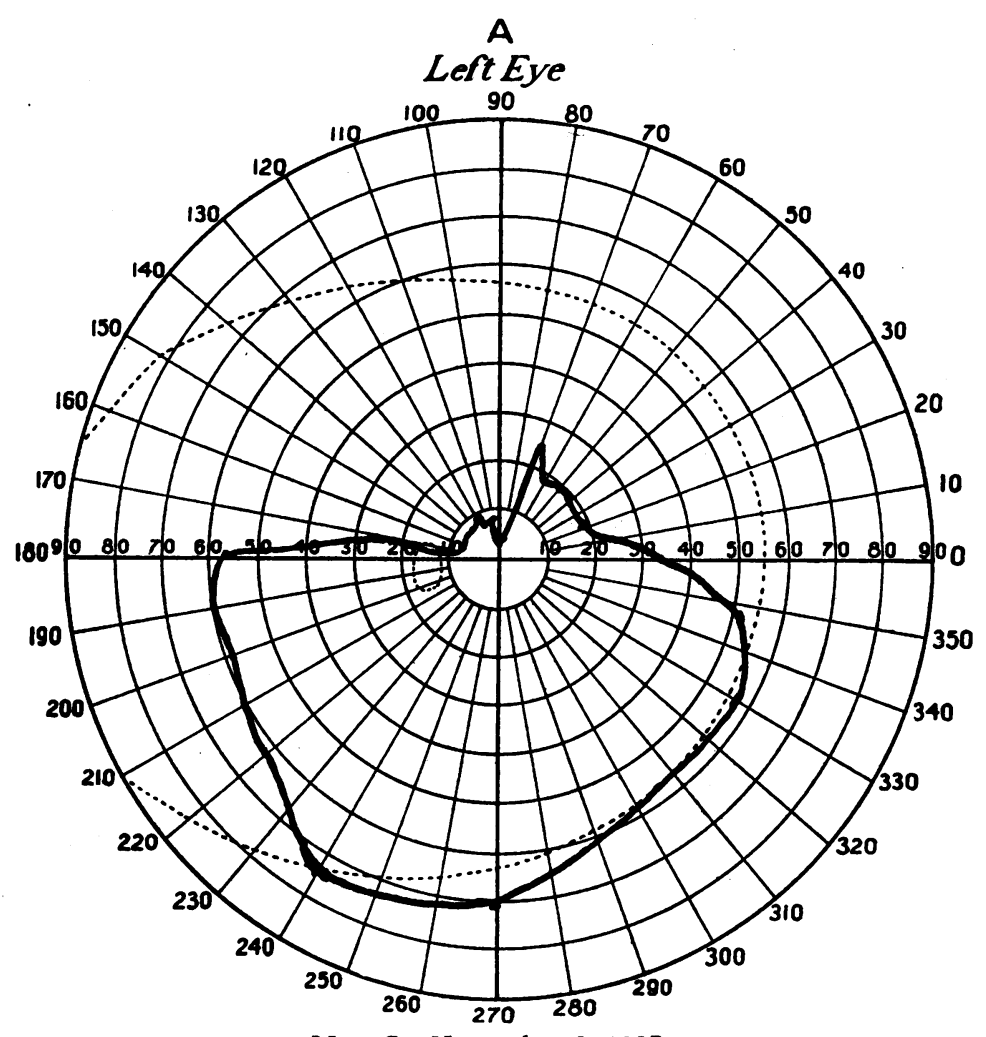

Mrs. C., November 8, 1937.

The patient left hospital on November 5, 1937, and my notes on her condition at the time were :

Fundi-discs yellowish-red with very indistinct edges, changes all over, pigmentation in spots, points of exudate involving the maculae as well, no detachments to be seen.

Vision-

R. 6/60 with -1.0 D.sph. with -1.5 D.cyl. $y \quad 6 / 60$ (vertical line
I. 6/60 with -1.0 D.sph. with -1.5 D.cyl. $y_{135} 6 / 60$.

Fields-much loss in the upper and inner fields (attached). Internal treatment was continued as before and rest as complete as possible ordered.

The patient was seen from time to time and her sight was found to be gradually increasing, both in acuity and extent of fields.

On April 9, 1938, unilateral headaches were again complained of-the fundi remained unaffected. A few spots of " K.P." were noticed in both eyes. 
The sphenoidal sinuses were reported to be clear, but the tonsils were infected and removal of them was recommended.

The tonsils were dissected out by Dr. A. M. de Silva on May 13,1938 , and shortly after the eyes cleared up completely. Similar attacks continued from time to time, lessening each time.

When last seen on April 26, 1939, the condition was very satisfactory.

Vision--
R. $-2 \cdot 0$ D.sph. with -1.5
L. -1.75 D.sph. with -1.5 D.cyl. $\downarrow 6 / 6$
(1) J.2, with difficulty.

The fundi remained free of further trouble, but showed appearances very similar to those seen on November 5, 1937.

Case 2.-Miss J. K., aged 28 years, a teacher, consulted me about June 9, 1939, complaining of blindness in her left eye of about four days' duration.

HisToRy.-Slight attack of "cold" about a fortnight before, which the patient thought was influenzal. About a week after that noticed a blur before left eye which she tried to wipe off from time to time. As it was getting worse she saw her doctor who advised her to have a carious left upper central incisor removed, and treated her left eye. This was done but the condition continued to get worse, till on the day she saw me she said she was blind in that eye.

Personal History.-Quite good, no illness of note. Slight menstrual irregularity from time to time. Well developed and on the stout side. Active in habits.

ON Examination. - L.E. movements quite normal. Lids, conjunctiva, cornea, anterior chamber, normal, pupil somewhat dilated (No. 4) and absolutely inert to light and accommodation and no consensual reaction. Lens and vitreous clear. Disc very deeply congested, rest of fundus showed nothing abnormal, except that the veins were slightly full.

Right eye quite normal. No tenderness in either eye on pressure.

Vision-R. 6/6.

L. not even p.1. T.n. R. and L.

The left upper central incisor had been extracted and the wound was clean.

The patient was admitted to hospital the same morning and given gutt. atrop. with fomentations, sod. salicyl. and iodides in large doses.

Acetyl-choline injection daily and diathermy to her eye.

On the third morning there was a glimmer of light noted in that eye. On the fourth morning the patient was just able to see fingers at 6 inches. During the four days she was in hospital, all 
the usual blood, urine and X-Ray examinations were carried out, with negative results. The patient was very thoroughly examined for any general disease, particularly with reference to nervous or endocrinal origin, and nothing found. Finally, Dr. A. M. de Silva examined her sphenoidal sinuses and reported deep congestion, indicating infection, and advised early operation. She was transferred to the General Hospital and was operated on June 13, 1939, under local anaesthesia.

She continued to remain under Dr. A. M. de Silva's care while being treated for her nose condition, and at the same time was given diathermy to her eye, acetyl-choline from time to time, and later iodides. She left hospital on July 7, 1939, with the nose condition healed and her vision had returned to nearly normal.

This patient was last seen by me on or about September 26, 1939. Her condition then was :

Vision-

R. 6/6 J.1. Right fundus normal.

L. 6/6 J.1. Left fundus, a slight paleness of disc-rest clear.

T.n. R. and I. Pupil left eye normal. Field of left eye normal.

\section{Observations}

These two cases show interesting points :

1. The infection of the sphenoidal sinuses appears to have resulted from a mild attack of influenza, not an unknown association.

2. The infective processes of the sinuses did not disclose frankly purulent discharge-instead a very deep congestion in both cases, with a bead of pus showing on one side in the first case. This in itself is striking, showing the extent to which damage to the optic nerves could result without the presence of frank suppuration.

3. Detachment of the retinae in septic cases is rare-in the case reported there is, however, the added factor of one ultra-short wave treatment which might have had a bad effect, or the shock following on operation, though one could scarcely see the connection in this last instance. At the time of the operation it was thought advisable to operate in stages as there was an idea that the operation might result in too severe a reaction.

4. Complete reposition of the retinae without any surgical measures directed to the eyes, and in consequence good vision. The patient was extremely amenable and is happy in the result. I have in another connection (after cataract operation) mentioned complete rest in the semi-recumbent position in cases of detachments of the retinae, with very good results, and consider this 
method should be given a thorough trial in those cases where no tear can be seen. It means a great deal of patience on the part of patient and medical man, but the satisfactory result more than compensates for this.

5. It has been my experience in more than one case of inflammation of the optic nerve that where the cause of the trouble cannot be definitely traced and the condition does not respond to treatment, sufficient " blood-letting" from a high operation in the nose often tends to bring about favourable results.

\section{ROBERT BRUDENELL CARTER}

BY

R. R. JAMES

WOODBRIDGE

BRUDENELL CARTER occupied a position intermediate between the giant founders of modern ophthalmology, such as Bowman and the elder Critchett, and the more modern consolidators of our science, such as Nettleship and William Lang. He was born in the same year as Sir Jonathan Hutchinson. Bowman and Critchett were roughly 12 and 11 years his senior, while Nettleship was about 17 years his junior.

Carter was born on October 2, 1828. He came of a very old family, one branch of which was long settled at St. Columb Major, in Cornwall. ${ }^{1}$ His own researches into his family history traced his descent from an Esquire of Higham, Beds. in the time of Edward the Fourth. ${ }^{2}$ Among his ancestors were some distinguished men and women. His great aunt was Elizabeth Carter, the poetess and translator of Epictetus whose "I canna be fashed" evoked the scorn of Miss Matty Jenkyns, in Cranford. His grandfather was the Rev. Henry Carter, Rector of Little Wittenham, Berks. for more than half a century, and his paternal grandmother was descended from John Wallis, F.R.S., the astronomẹr and mathematician. Carter's father was a Major in the Royal Marines. His mother died in giving birth to R. B. Carter and in consequence the father took little interest in the baby, who owed his christian names to the kindness of a friend of Major Carter, the then Earl of Cardigan.

Carter was educated at private schools and began his professional education as an apprentice to a general practitioner. He subsequently entered the London Hospital as a student and qualified M.R.C.S. in 1851. In the following year he took the L.S.A., these two diplomas constituting at that time the usual double qualification. 